\title{
EDUCAÇÃO AMBIENTAL NAS SÉRIES INICIAIS
}

\author{
Darley Kury Marques de Amorim ${ }^{1}$ \\ Deysiane Silva da Luz Oliveira ${ }^{2}$ \\ Marelucia Rodrigues de Amorim ${ }^{3}$ \\ Sandra Gusmão de Almeida ${ }^{4}$
}

RESUMO: este artigo tem como tema a educação ambiental, tem como linha de pesquisa os anos iniciais do ensino fundamental, resulta sobre a preocupação crescente acerca das questões ambientais. enfatiza-se que a importância da educação ambiental nas escolas, como de reduzir os impactos de ações nos vários ecossistemas naturais. tais ações devem ser aplicadas na prática docente para transformação conceitual de crianças nos seus primeiros anos de vida, sendo que conceitualmente a educação ambiental promove o ensino e modificação de ações frente à conduta dos cidadãos acerca de suas ações que acarretam mudanças e destruição do meio ambiente. é de suma importância as práticas pedagógicas desenvolvidas em sala de aula que incentivem ações sustentáveis inovadoras, o docente consegue ampliar seus canais de comunicação com as crianças, fazendo as mesmas entendam na prática, que atitudes podem ser tomadas assim sendo, para a realização deste trabalho, foi utilizado à pesquisa bibliográfica, com base na reflexão e leituras de livros, artigos, revistas e sites, bem como pesquisa de autores referências neste tema. o educador responsável pelo ensino da educação ambiental assume caráter formativo na visão ambiental de seus alunos, possibilitando a moldagem da personalidade e consciência social. deste modo, esse artigo visualiza ações promovidas pelo educador que possa trabalhar a educação ambiental, com os alunos, enumerando possíveis exemplos de ações o conhecimento de mundo, do meio ambiente, da preservação ambiental.

Palavras-chave: Educação Ambiental. Prática docente. Ecossistemas naturais. Educação Ambiental, Ações sustentáveis inovadoras. Educador.

ABSTRACT: This article has as its theme Environmental Education, its research line is the Early Years of Elementary School, and results from the growing concern about environmental issues. It emphasizes the importance of environmental education in schools, how to reduce the impacts of actions on various natural ecosystems. Such actions must be applied in teaching practice for the conceptual transformation of children in their first years of life, and conceptually environmental education promotes the teaching and modification of actions against the behavior of citizens about their actions that lead to

\footnotetext{
r Graduada em Pedagogia pela Fundação Universidade Federal de Mato Grosso do Sul - FUFMS, Especialista em Educação Infantil e Alfabetização pelo Instituto Cuiabano de Educação - ICE.

${ }^{2}$ Graduada em Pedaogia pelo Centro Universitário de Várzea Grande - UNIVAG.

3 Graduada em Pedagogia pela Universidade Estadual do Tocantins - UNITINS, Especialista em Atendimento Educacional Especializado pela Fundaçao Universitária Iberoamericana - FUNIBER.

${ }^{4}$ Graduada em Pedagogia pelo Centro Universitário de Várzea Grande - UNIVAG, Especialista em Gestão e Segurança Pública pela Universidade do Estado de Mato Grosso - UNEMAT.
} 
changes and destruction of the environment. It is extremely important the pedagogical practices developed in the classroom that encourage innovative sustainable actions, the teacher is able to expand their communication channels with children, making them understand in practice, what attitudes can be taken, was used for bibliographical research, based on reflection and reading of books, articles, magazines and websites, as well as a search for reference authors on this topic. The educator responsible for teaching environmental education assumes a formative character in the environmental vision of its students, enabling the molding of personality and social awareness. Thus, this article visualizes actions promoted by the educator who can work on environmental education, with students, listing possible examples of actions: knowledge of the world, the environment, and environmental preservation.

Keywords: Environmental Education. Teaching practice. Natural ecosystems. Environmental Education, Innovative Sustainable Actions. Educator

\section{INTRODUÇÃO}

O tema desenvolvido neste artigo é a Educação ambiental, tem como linha de pesquisa os Anos Iniciais do Ensino Fundamental. Este artigo resulta sobre a preocupação crescente acerca das questões ambientais, principalmente causadas pelo desrespeito, bem como dos impactos das ações humanas nos diferentes ecossistemas naturais, se deve aplicar na docência séries iniciais do ensino fundamental buscando uma mudança conceitual das crianças em seus primeiros anos de vida.

A educação ambiental incide no ensino e transformação dos cidadãos abordando suas ações ocasionando tais modificações no meio ambiente, sendo que não foi notada esta preocupação no decorrer do estágio presencial, disciplina ou matéria que abordasse a temática.

A realização deste artigo justifica-se na necessidade de promover a conscientização ambiental dos alunos desde a formação inicial, àquela aplicada às séries iniciais. As práticas atuais de educação ambiental não satisfazem aos anseios de pais, professores, alunos e sociedade em geral.

Portanto, a temática foi selecionada diante da importância de se trabalhar esse tema em sala de aula, sua relevância social, educacional, pois devemos empregar à sociedade, nosso papel de educadores e da nossa responsabilidade social, pela educação ambiental. Outro ponto importante que contribuiu para analisar tal reflexão, diz respeito à experiência levantada no decorrer do estágio presencial, observando a carência de disciplinas ou matérias que colocassem em prática de reflexão e abordando a temática 
proposta neste projeto. Essa circunstância nos fez buscar o aprofundamento dessa problemática, com o objetivo de apontar possíveis práticas que possam ser aceitas nas primeiras séries relacionadas à educação ambiental.

Como problematização, para que a Educação Ambiental se efetive, é indispensável que a escola assim como os professores estejam empenhados com as práticas e com uma proposta de Educação Ambiental. O trabalho com os estudantes nas séries iniciais favorece a importância de fatores e situações que realmente ajudem a desenvolver a capacidade crítica em relação ao meio ambiente.

Como referencial teórico, buscou-se autores que tratam do tema tais como: Barcelos (2003), Brasil, (1988), Gebran (2004), Jacobi (2003), Loureiro (2012), Medeiros, (20II), Rodrigues (20II), Sato, (2000), Vasaki, Mergulhão (1998), entre outros.

\section{DESENVOLVIMENTO}

Segundo o Ministério do Meio Ambiente do Brasil, a educação ambiental pode ser compreendida como os processos de construção de valores sociais, conhecimentos destinados à preservação e uso dos recursos naturais com consciência, gerando assim qualidade de vida e o salvamento das espécies. Esse conceito nos leva ao entendimento dos aspectos básicos referente a educação ambiental nas escolas municipais.

O aparecimento desta preocupação ambiental surgiu a partir dos fortes impactos negativos causados por ofensivas humanas apontadas ao meio ambiente, restringindo assim o volume de recursos ambientais disponíveis a subsistência humana.

De acordo como IBRAM (Instituto Brasileiro Ambiental), a melhor forma de abranger conceitualmente a temática proposta está na análise da seguinte proposição acerca da sustentabilidade.

\footnotetext{
O tema da sustentabilidade confronta-se com o paradigma da "sociedade de risco". Isso implica a necessidade de se multiplicarem as práticas sociais baseadas no fortalecimento do direito ao acesso à informação e à educação ambiental em uma perspectiva integradora. E também demanda aumentar o poder das iniciativas baseadas na premissa de que um maior acesso à informação e transparência na administração dos problemas ambientais urbanos pode implicar a reorganização do poder e da autoridade (JACOBI, 2003, p. 192).
}

Vasaki \& Mergulhão (1998, p. 17),“Não é preciso ser professor, muito menos da área de biologia, para ser eleito educador ambiental. Basta ter o ideal de usar parte de sua 
vida mostrando, com palavras e exemplos, a importância de ser um cidadão consciente e ativo em relação ao seu meio".

Segundo Munhoz (2004) enfatiza a relevância do educador nas práticas pedagógicas realizadas em sala de aula, pois ele é um agente promotor de reflexões e principalmente, o elo entre as diversas teorias e práticas. Desse modo, os jovens são instigados ao processo reflexivo com vistas à mudança no comportamento individual da criança que impacta no contexto social. $\mathrm{O}$ autor também apresenta alguns artifícios que os professores utilizam e podem ampliar para melhorar a compreensão dos alunos acerca das práticas mais adequadas a preservação ambiental, tais como: leitura e trabalhos de pesquisas escolares com debates.

Aplicando os exercícios pedagógicos do docente, as crianças poderão entender na prática extensiva, os problemas que afetam o bairro e a cidade onde residem desta forma promovendo ações individuais e coletivas para proteger, preservar e cultivar sustentavelmente os bons hábitos de consumo. Desse modo, a imagem do professor é extremamente importante no contexto de formação do caráter, personalidade e consciência social por ser ele o responsável pela inclusão das idéias práticas e simples, que possibilitem à juventude, um futuro melhor.

Os educadores, em geral, não atribuem ao tema à devida importância e se sentem despreparados para lidar com questões relacionadas às possibilidades e problemáticas ambientais no currículo escolar. Por conseguinte, a Educação Ambiental tem sido tratada de forma pontual, restringindo-se às informações dos livros didáticos, às datas comemorativas e, no geral, projetos desarticulados da realidade social (BASTOS, 2004, p. 13).

Lopes de Sá (1999), manifesta certa preocupação com a formação inicial do cidadão ao afirmar que há uma consciência mundial em marcha, cuja formação se acelera e que condena a especulação gravosa da riqueza tão como o uso inadequado de utilidades, como fatores de destruição do planeta e lesão à vida dos entes que povoam o mundo. $O$ registro de tal preocupação comprova claramente que o habito produtivo e de consumo da população necessita pensar mais nos aspectos ambientais, pois o que se observa que empresas e diversas indústrias utilizam os recursos sem se atentar com a limitação destes recursos e com o fim de sua renovação.

Alguns outros autores e bibliografias exemplificam apresentando, inclusive, dados estatísticos que comprovam a importância e a relevância da mudança de habito de 
consumo da população, pois a poluição ambiental causada pela ação humana de transformação está causando múltiplos problemas ambientais gravíssimos, que culminam contra a existência humana.

De certo modo outros autores avisam sobre as medidas educativas mais urgentes, promovendo na educação de crianças nas séries iniciais, para impedir o aumento desenfreado da degradação ambiental, imposta pelo consumo capitalista humano. Essa preocupação reside do modelo industrial aplicado aos diversos insumos de produção para a criação de diversos produtos industrializados, sendo que se cultivarmos a educação enquanto criança, sua postura como adulto possivelmente possa refletir com ações positivas de preocupação e respeito à biodiversidade das espécies.

Nessa linha de raciocínio Frers (200o) reafirma a importância de levar ao conhecimento da população, que cada vez mais, as nossas ações são as causas principais dos problemas vividos hoje de aquecimento global e descongelamento das placas de gelos, levando assim a extinção de diferentes espécies de animais. Para que isso ocorra, este autor deixa claro a importância da aplicação das políticas delimitadas, já no ensino básico, para organizar professores e estudantes, prevenindo desde cedo contra a prática abusiva e desrespeitosa de degradação ambiental, pois somente assim será possível mudar o comportamento da sociedade.

De acordo com os conceitos básicos da educação ambiental, é valido esclarecer que o foco de aplicação das reflexões propostas, são incluídas nas séries iniciais (acima de 6 anos) onde se encontram no estágio de absorção do conhecimento, pois a partir desse momento, que o ensino assume um caráter mais formal e transformador. Nessa etapa o conceito do mundo exterior começa a ganhar maiores definições e a criança tem a tendência de absorver com maior profundidade todas as temáticas trabalhadas pelos professores.

A exposição de três argumentos básicos que estão ligados diretamente as escolhas por essa temática: os valores sociais aplicados à educação ambiental ainda no seio familiar, as diversas formas de preservação ambientais aplicáveis aos ambientes escolares e a sustentabilidade geradora da prosperidade de espécies de plantas e seres vivos.

A aplicação da educação ambiental às séries iniciais, as crianças recebem a base instrutiva que aliado às suas experiências iniciais de vida, cria conceitos norteadores para 
sua postura, aperfeiçoando os perfis de condutas sociais adequados aos princípios morais existentes na sociedade. Esse processo, ajuda na convivência do ser humano com o meio ambiente, principalmente com os recursos diversos que podem ser utilizados para o consumo humano de maneira correta, entretanto é preciso que o sistema educacional como um todo faça parte desse processo.

[...] sobre Educação Ambiental, o próprio sistema educacional precisa ser redimensionado, de uma organização de currículo escolar com matérias estanques que gera a visão fragmentada, sem relações, conexões com o entorno e a vida propriamente dita do educando, para um sistema educativo onde os objetivos educacionais propostos $e$ as intenções que permeiam as ações sejam o desenvolvimento de capacidades, competências e valores que se pretende desenvolver nos alunos (GEBRAN, 2004, p. 102).

Deste modo a abordagem na educação ambiental nas séries iniciais possibilitará a criança a compreender sistematicamente às necessidades conceituais para a sua formação, além da criação do modelo mental de ações corretas que devem ser tomadas para preservar o meio ambiente, dando-nos a oportunidade de propor reflexivamente a adoção de maneiras adequadas que ampliem seus conhecimentos acerca das práticas positivas e negativas.

Contudo, a abordagem nas séries iniciais deve ser mais adequada à sua forma de integração com o meio para que possam resolver situações-problemas, explicando a necessidade do desenvolvimento de estratégias aplicadas à metodologia da educação ambiental, que sejam: atrativas, criativas e inovadoras, chamando assim a atenção dos alunos sobre a relevância da temática.

Com a prática pedagógica criativa pode ocorrer em diversos ambientes, como: nos corredores, dentro de sala de aula e nos pátios da escola, entretanto necessita de um planejamento estratégico bem definido que comprove claramente, instrumentos necessários, objetivos esperados, temáticas trabalhadas junto aos alunos, pois desse modo, as práticas ambientais de ensino podem contribuir de forma correta causando maior efeito e principalmente nas crianças de séries iniciais, enfocadas nesse estudo.

De acordo com Daminelli (2oro, p. 87) as atividades de Educação Ambiental devem contemplar o proposto no ensino formal.

As atividades de Educação Ambiental que complementam a proposta do ensino formal são fundamentais à construção da cidadania dos educandos. Os ambientes naturais contribuem na ampliação das percepções dos alunos, uma vez que as vivências possibilitam a reflexão sobre dimensões políticas e a busca de soluções 
aos problemas ambientais.Porém, para que sejam realmente efetivas, as práticas de Educação Ambiental não formais (realizadas fora do âmbito escolar) devem acompanhar as propostas de conteúdo estabelecidas pelos órgãos cabíveis; no caso, as secretarias estaduais e municipais de Educação e, de forma mais completa, o Ministério da Educação e do Desporto (MEC).

Logo então se torna claro que os volumes excessivos de tecnologias e informações disponíveis massificam indiscriminadamente incentivando o consumismo de forma muito precoce na formação das crianças. Este quadro preocupante tem se tornado temas de muitos debates, porém, pouco tem sido feito em termos práticos para confrontar esse grave problema, gerando um grande desafio dos educadores, de unir forças com pais e comunidade escolar, em busca de objetivos práticos comuns para frear o consumismo em função de um meio ambiente saudável e equilibrado.

Rodrigues (20II) deixa claro em sua obra sobre a importância de conhecer o mundo, afirmando que a criança deve partir de sua realidade exterior a criticando e dialogando com todos os envolvidos com sua formação para ampliar sua visão de mundo.

Nesse ponto, o aluno tem a se sensibilizar, desde a série inicial, quanto à importância no que se diz respeito ao ambiente onde vivemos, ensinando a compreender a partir de um enfoque lúdico e estratégico, as dinâmicas do meio ambiente através de análise e reflexão de causas e conseqüências nas relações do homem com o meio.

Descrever os objetivos exclusivos a necessidade do desenvolvimento dos jogos estratégicos, que levem o aluno a reflexão conforme as atitudes e conseqüências dentro do meio inserido, também a criação de dinâmicas que estimulem a reflexão sobre hábitos saudáveis e que contribuam para melhor qualidade de vida e preservação do meio ambiente, além do estimulo a criatividade artística, visando o desenvolvimento prático que contribua para um ambiente saudável e equilibrado.

Sendo assim, podemos demonstrar que já existem leis e normas nacionais que fortaleçam e institucionalizem a aplicação dos ensinamentos de educação ambiental, pois foram criados inclusive órgãos que façam o controle e combate às nocivas ao meio ambiente, evidenciado em 1973 com o Decreto no 73.030, que designa na esfera executiva do poder público, a Secretaria Especial do Meio Ambiente (SEMA), vinculada ao Ministério do Interior.

Art. I․ Fica criada, no Ministério do Interior, subordinada diretamente ao Ministro de Estado, a Secretaria Especial do Meio Ambiente (SEMA), órgão autônomo de administração direta, nos termos do artigo 172 do Decreto-Lei no 
200 , de 25 de fevereiro de 1967 , com a redação dada pelo Decreto-Lei no 900 , de 29 de setembro de 1969 , orientada para a conservação do meio ambiente, e o uso racional dos recursos naturais.

Por meio da criação do órgão, se tornou possível esclarecer e reformar a educação do povo brasileiro para o uso adequado dos recursos naturais, com a perspectiva da conservação do meio ambiente.

Mais um passo importante está em anexo à institucionalização da temática e a criação da Política Nacional do Meio Ambiente (PNMA) em 1981, colocando no âmbito legislativo, a necessidade de incluir na educação ambiental em todos os níveis de ensino, juntamente na educação comunitária, objetivando a capacitação dos cidadãos para a participação ativa na defesa do meio ambiente, evidenciando a capilaridade que se desejava imprimir a essa prática pedagógica.

Conforme a abordagem da educação ambiental, a Constituição Federal de 1988, em seus direitos estabelece no inciso VI do artigo 225, a necessidade de "promover a educação ambiental em todos os níveis de ensino e a conscientização pública para a preservação do meio ambiente" (PRONEA, 2005, p. 2).

Art. 225 Todos têm direito ao meio ambiente ecologicamente equilibrado, bem de uso comum do povo e essencial à sadia qualidade de vida, impondo-se ao Poder Público e à coletividade o dever de defendê-lo e preservá-lo para aos presentes e futuras gerações.

Com a importância desta temática no Brasil se tornou muito mais evidente com a criação em 1992 do Ministério do Meio Ambiente (MMA), e em julho do mesmo ano, foi criado o IBAMA o qual instituiu os Núcleos de Educação Ambiental em todas as suas superintendências estaduais, visando operacionalizar as ações educativas no processo de gestão ambiental na esfera estadual. (PRONEA, 2005, p.23)

Em dezembro de 1994, em função da Constituição Federal de 1988 e dos compromissos internacionais assumidos com a Conferência "Rio 92", foi criado pela Presidência da República, o Programa Nacional de Educação Ambiental (PRONEA), compartilhado pelo então Ministério do Meio Ambiente, dos Recursos Hídricos e da Amazônia Legal e pelo Ministério da Educação e do Desporto, com as parcerias do Ministério da Cultura e do Ministério da Ciência e Tecnologia. Esse programa foi executado pela Coordenação de Educação Ambiental do MEC e pelos setores correspondentes do MMA/IBAMA, responsáveis pelas ações voltadas respectivamente ao 
sistema de ensino e à gestão ambiental, embora também tenha envolvido em sua execução outras entidades públicas e privadas do país. (PRONEA, 2005, p. 25)

Mesmo com vários avanços cronológicos enumerados acima, a Constituição Federal brasileira ergueu ainda mais o status do direito à educação ambiental, ao mencioná-la como peça fundamental a qualidade de vida ambiental. Atribui-se ao Estado o dever de "promover a educação ambiental em todos os níveis de ensino e a conscientização pública para a preservação do meio ambiente" (art. 225, §I ${ }^{\circ}$, inciso VI), passar a existir, este direito constitucional de todos os cidadãos brasileiros terem acesso à educação ambiental. (PLANO NACIONAL DE EDUCAÇÃO - PNE).

Os dados exibidos se explicam quando analisamos a abordagem de Sato (200o, p. 13), pois se necessita de atenção e urgência para a análise e controle dos problemas ambientais. A problemática tornou possível que diversas entidades governamentais abrissem debate acerca da necessidade de resposta às necessidades sociais crescentes. Essa preocupação repercutiu na criação de diversos cursos de extensão para a formação de professores, através de diversas ações, principalmente de palestras e cursos, para preparar os professores para a abordagem sistemática na sala de aula. Enfatizando principalmente a necessidade de sair do espaço de sala de aula em alguns momentos, para estendê-la aos parques, museus ou horto florestal e espaços sociais das comunidades.

Perante a exposição destes argumentos, entende-se que as inclusões das propostas ambientais no cotidiano educacional das séries iniciais, vão além do cumprimento legislativo vigente decretado para a prática pedagógica escolar, sendo relacionada ao compromisso social das instituições de ensino, e em particular, das escolas de educação Infantil em proporcionar o diálogo consciente, tendo como premissas básicas, propostas pedagógicas expositivas e instrutivas de princípios que vão ao encontro as preocupações ambientais. Desse modo, torna-se relevante a criação de mecanismos de ensino que reflitam acerca das ações cidadãs, que afetam a vida no meio ambiente.

Seguindo esta mesma ideologia vários grupos de profissionais da educação têm despendido seus conhecimentos e esforços na busca por estratégias que fortaleçam os entendimentos da educação ambiental no cotidiano escolar, oferecendo maior credibilidade a sua adoção à prática escolar com atos educativos que sejam mais assertivas. 
Com o aprofundamento na sistemática da educação ambiental surgiu da busca incansável pela reparação aos impactos ocasionados pela ação humana no meio ambiente, também da compreensão que é mais eficiente à aplicação da educação ambiental nas escolas para as crianças das séries iniciais, do que para o cidadão já formado.

O conceito prático é a quebra dos paradigmas abordados sobre as questões ambientais quanto ao apontamento dos incômodos e a necessidade do desejo por mudanças ou melhorias na qualidade do ambiente vivido pelo ser. Desta forma o costume a educação ambiental se torna relevante como uma ciência por necessitar o desejo do aluno, assim impulsionando o enriquecimento científico e teórico para estimular e motivar os educadores acerca da relevância de seu papel social.

Determinados exemplos que foram visualizados durante o período de estágio que beneficia a quebra de paradigmas, estão no plantio e cultivo dentro das escolas de arvores e diversas plantas, além da integração com a comunidade ao redor das escolas públicas municipais.

Conforme determinados pensamentos propostos à educação infantil frente às mudanças de conscientização ambiental têm contribuído para o retorno da vivência escolar de diversos membros sociais de maneira cronológica. Essa ação está ocorrendo, graças à participação social em diversas práticas pedagógicas que incentivem o diálogo acerca dos cuidados e benefícios que a prática da educação ambiental traz para a qualidade de vida nas cidades.

Através dessas experiências, trilhamos acertos e erros, os quais nos ensinam muito sobre a maneira mais adequada à prática pedagógica da educação infantil articulada com as concepções ambientais. Assim, o processo não se resume na aceitação curricular ambiental crítica, mas numa transformação do espaço escolar de modo que ela seja capaz de praticar aquilo que os documentos curriculares carregam enquanto concepções.

Acerca dos fatos, a prática pedagógica transcende para além das próprias palavras instrutivas, pois através dela são criadas ações que culminam na mudança do contexto social, principalmente por proporcionar às crianças diálogo e debate sobre as idéias, objetivando conjuntamente progredirmos perante as situações e problemáticas ambientais que ultrapassamos espaço da escola. O que instiga é exatamente como isso pode acontecer, mas tratando-se de educação ambiental existem várias metodologias, pois elas 
diferenciarão cada indivíduo, ambiente e cultura e possibilitarão elementos que norteiam o fazer pedagógico.

Movimento coletivo de ampliação do conhecimento das relações que constituem a realidade, de leitura do mundo, conhecendo-o para transformá-lo e, ao transformá-lo, conhecê-lo. Dinâmica escolar que reconhece as especificidades de professores, pais, alunos e demais integrantes da comunidade escolar, mas que não pensa o acesso à informação e à cultura dissociada da contextualização da prática e da recriação da própria cultura (LOUREIRO, 20I2, p. 80).

Diante dessas atitudes pedagógicas, diversas escolas vêm repensando sua postura, debruçando-se perante os elementos curriculares do cotidiano que culminam com os princípios da educação ambiental formadora dos processos em ações didáticas que chamem a atenção do aluno.

[...] o que se espera da escola é que contribua para que as crianças cresçam na vivência de valores e não apenas na sua aceitação e/ou aprendizagem, até porque não se ensinam valores. Há que vivê-los e, de preferência em comunidade [...].

Observando-se as vivências dos pensamentos dos ecologistas, identificamos a possibilidade de incorporarmos às práticas cotidianas, ações que priorizem alguns processos fundamentais como condutores da prática pedagógica: o diálogo, respeito com o outro, vivências ambientais e democracia.

Ainda refletindo sobre as ações assintomáticas, a sustentabilidade se aplica integralmente à educação ambiental, por promover de ações coerentes que enfoquem as necessidades dos cidadãos, sem comprometer a existência, o futuro e as próximas gerações.

De maneira geral, a sustentabilidade depende da ação humana que deve se ligar ao uso racional dos recursos materiais, sem que isso impacte negativamente na vida humana ou na natureza, pois se deve buscar o equilíbrio, deixando de agredir o meio ambiente, graças à aplicação de idéias criativas e que não sejam danosas ao convívio social. Portanto, através da sustentabilidade se consegue a utilização dos recursos naturais inteligentemente para que sejam mantidas boas condições para uso em futuras gerações.

Assim, a idéia de sustentabilidade implica a prevalência da premissa de que é preciso definir limites às possibilidades de crescimento e delinear um conjunto de iniciativas que levem em conta a existência de interlocutores e participantes sociais relevantes e ativos por meio de práticas educativas e de um processo de diálogo informado, o que reforça um sentimento de co-responsabilidade e de constituição de valores éticos. Isto também implica que uma política de desenvolvimento para uma sociedade sustentável não pode ignorar nem as 
dimensões culturais, nem as relações de poder existentes e muito menos o reconhecimento das limitações ecológicas, sob pena de apenas manter um padrão predatório de desenvolvimento (JACOBI, 2003, p. 195).

Analisando-se profundamente a idéia proposta por Jacobi, existe a necessidade crucial de adotar uma política educativa que instrua efetivamente a criança, durante sua formação, para que sua ação transformadora no futuro não impacte negativamente na vida da população afetando a existência coletiva da espécie humana.

Portanto, a educação ambiental é fundamental para a formação das crianças na escola, principalmente nas séries iniciais, por promover o desenvolvimento pessoal do cidadão, procurando tomar decisões com base em reflexões acerca da adoção de ações individuais que quando analisadas coletivamente, promovem a interação socioambiental e culminam na melhoria da qualidade de vida e existência da sociedade.

\section{CONCLUSÃO}

No decorrer do desenvolvimento deste artigo, permaneceu evidente que ações simples e criativas devem ser promovidas, para que os alunos de séries iniciais tenham consciência do papel que cada indivíduo deve prestar a sociedade.

Os educadores devem abranger que a educação ambiental auxiliará a prevenção da qualidade de vida ambiental, principalmente por garantir o acesso as mais diversas fontes de recursos, graças às ações de combate ao uso desenfreado dos recursos naturais.

O professor tem o papel essencial de estar sempre se renovando obtendo novos conhecimentos e práticas de planejamento, para que a temática não tenha um caráter meramente teórico, mas voltado para a prática de vida da criança no contexto social. Sua importância também é observada durante todo o projeto ao evidenciar que o professor tem a função de se atentar às necessidades das crianças, focalizando inclusive, em ações incorretas que podem ser trabalhadas e modificadas para reduzir as conseqüências desastrosas na vida adulta que prejudiquem a vida humana.

Deste modo, a educação ambiental não pode ser analisada de modo superficial, residindo-se aí, o foco de atuação proposto pelo projeto durante todas as suas etapas de execução.

Para conseguir o sucesso da aplicação da educação ambiental depende da conscientização social e o aumento na mobilização atualmente vigente, pois desse modo, o aprendizado alcançará seu fim e razão de existir. 
Assim sendo, considera-se a educação ambiental como um instrumento de mudança social da postura individual, que deve ser aplicado às séries iniciais para que os cidadãos tenham consciência sobre sua formação educacional, além da valorização dos profissionais da educação que se dedicam ao estudo, pesquisa, desenvolvimento e aplicação aos alunos dos conhecimentos adquiridos.

\section{REFERÊNCIAS}

BARCELOS, Valdo. Infância, Imaginação e Ecologia: que lugar ocupam na formação de professores e professoras? II Simpósio Sul Brasileiro de Educação Ambiental. Itajaí, SC: 2003.

BRASIL. Constituição Federal. Constituição da República Federativa do Brasil. Brasília, DF: Senado, 1988.

BRASIL. Lei no 9.795: PNEA - Política Nacional de Educação Ambiental. Presidência da República. Brasília, DF: 1999.

BRASIL. Decreto no 73.030 (10973). Presidência da República, Brasília, DF.

DAMINELli, Rebeca de Mattos. Silva, Sandro Menezes. Casos de Sucesso na Educação Ambiental: casos de i a ro. Curitiba: IESDE Brasil S.A. 2010.

GEBRAN, Raimunda Abou (org). Contexto escolar e processo ensino-aprendizagem: ações e interações. São Paulo: Arte \& Ciência. 2004.

IBRAM. O que é Educação Ambiental? Disponível em: http://www.ibram.df.gov.br. Acesso em 25/10/2021.

FRERS, Cristian. En busqueta de una educación ambiental. Disponível em: www.estrucplan.com.ar. Acesso em 25/10/2021.

JACOBI, Pedro. Educação Ambiental, Cidadania e Sustentabilidade. Cadernos de Pesquisa, n. II8, março/ 2003. Disponível em http://www.scielo.br acesso em 25/ro/202I. 
LOUREIRO, Carlos Frederico B.. Educação Ambiental Crítica: contribuições e desafios: Vamos cuidar do Brasil: conceitos e práticas em educação ambiental na escola. Brasília, 2007 .

MEDEIROS, Aurélia Barbosa de. et al. A Importância da educação ambiental na escola nas séries iniciais. Revista Faculdade Montes Belos, v. 4, n. I, set. 20Ir. Disponível em http://www.terrabrasilis.org.br acesso em 25/10/2021.

MINISTÉRIO DO MEIO AMBIENTE. Conceitos de Educação Ambiental. Disponível em: http://www.mma.gov.br. Acesso em 25/10/2021.

MUNHOZ, Tânia. Desenvolvimento sustentável e educação ambiental. Disponível em: www.intelecto.net/cidadania/meio-5.html. Acesso em: 30/04/2016.

RODRIGUES, Cae. Educação Infantil e Educação Ambiental: Um encontro das abordagens teóricas com a prática. Revista Eletrônica Mesc. Educ. Ambient. V.26, 2011.

SANTOS, Aline Gomes dos; SANTOS, Crisliane Aparecida Pereira. A Inserção da Educação Ambiental no Currículo Escolar. Revista Monografias Ambientais - REMOA v. I5, n.I, jan-abr. 2016, p. 369-38o. Disponível em https://periodicos.ufsm.br acesso 18/o8/2018.

SATO, Michele. Formação em educação ambiental - da escola à comunidade. In: Panorama da Educação Ambiental no Brasil. Brasília: MEC, março de 2000.

VASAKI, Beatriz Nascimento Gomes; MERGULHÃO, Maria Cornélia. Educando para a conservação da natureza: Sugestões de atividades em educação ambiental. São Paulo: EDUC, 1998. 